\title{
The Convergence Analysis of Regional Growth Differences in China: The Perspective of the Quality of Economic Growth*
}

\author{
Linhai Mei, Zhihao Chen" \\ Department of Economics, School of Economics, Jinan University, Guangzhou, China \\ Email: tmeilh@jnu.edu.cn, ${ }^{* 15989278452 @ 163 . c o m ~}$
}

How to cite this paper: Mei, L.H. and Chen, Z.H. (2016) The Convergence Analysis of Regional Growth Differences in China: The Perspective of the Quality of Economic Growth. Journal of Service Science and Management, 9, 453-476.

http://dx.doi.org/10.4236/jssm.2016.96049

Received: August 5, 2016

Accepted: November 7, 2016

Published: November 10, 2016

Copyright $\odot 2016$ by authors and Scientific Research Publishing Inc. This work is licensed under the Creative Commons Attribution International License (CC BY 4.0).

http://creativecommons.org/licenses/by/4.0/ (c) (i) Open Access

\begin{abstract}
This paper develops a biennial Malmquist-Luenberger productivity index, in which it takes resources and the environment into account, and use a spatial econometric analysis to measure the Chinese provincial spatial convergence of the total factor productivity $(T F P)$ to conclude its decomposition. The empirical results show that: 1) China's TFP increase significantly in recent years, mainly driven by technical improvement; 2) there is nationwide conditional convergence of productivity except for diffusion in the northeast and east regions. Because of the large spatial differences amongst various areas in China, the convergence of different region is affected by different factors; 3) we expect that "resource curse" would present in the regions in China excluding east regions. "Pollution haven" exists in the Central and western areas, suggesting that the perspective of China's industrial environment is not optimistic; 4) the current ownership structure does not facilitate TFP growth, and industrial structure of inland areas limits local TFP growth. In general, if policy makers intend to converge the development gap between regions, assisting the developing areas to catch up with the relatively developed regions, it is crucial to improve the system of state-owned enterprise and the industrial structure, and government also needs to evaluate and test the effect of FDI rationally.
\end{abstract}

\section{Keywords}

Green TFP, Technological Progress, Convergence, Spatial Econometric

\section{Introduction}

Since the reform and opening-up policy from 1978, China's economic performs ama-

*This work was funded by case study projects of Enterprise transformation development of the institute for enterprise development, Jinan University (No. 12). 
zingly, and the economic society changes greatly, this phenomenon is called as "Chinese miracle" by scholars. Along with the rapid economic development, however, China's economic space layout changes greatly. In particular, the growth gap between regions has the trend to be deeper. Regional differences expanding not merely reduce the economic efficiency, but affect social stability. At present, China's economy is into the transformation stage with slow development, and regional economic development is entering a new period. In order to implement "the Belt and Road" strategy, and promote the regional economic innovation from theory to practice, how to identify the influencing factors of regional development difference, narrow the gap in development among regions and realize the regional coordinated development, has become a great hurdle to the government and academia.

As one of the hot topics of academic research, regional disparity is ubiquitous in the economic development. Academic circles generally believed that the keys of the dynamics of economic growth mainly include inputs, TFP and technological change and etc. In early 1990's most researchers thought that inputs play an important role to drive the economy growth. As the Neoclassical growth theory, the point of diminishing marginal returns is accepted by scholars, which makes researchers begin to pay close attention to the TFP. And a large number of empirical studies have shown that TFP, technological changes and efficiency variations are the main reasons for the differences in regional economic growth. The disparity of regional economic growth is mainly from two aspects. On the one hand, the parity of growth speed on the TFP, technological changes and efficiency variations. On the other hand, the disparity of the factors which influences on $T F P$, technological changes and efficiency variations. Due to the existence of spatial effect on the growth of $T F P$ and the influencing elements, we need to consider such spatial impact when we study the regional economic growth difference. For this reason, this article mainly discusses the $T F P$ convergence on a spatial framework.

To measure the TFP gap in China it is customary to evaluate the China's economic growth pattern. In fact, China's economic growth, to a large extent, depends on the high energy consumption, high emission and high pollution.

Figure 1(a) shows the growth rate of China's GDP, labor force, capital stock and energy consumption relatively to 1999 in the 1999-2012 periods. The figure shows that China's economic growth is accelerating from 1999, slower than capital growth, and influenced by the growth of population, but the growth of the labor is significantly slower than any others. The most remarkable of these is the growth of energy consumption, which is much faster comparing with the labor. Actually, along with China's GDP output value in 2012 is equal to 4.8 times of 1999, the energy input is equivalent to three times of 1999. As the driving force on China's economic development, the energy should be included in inputs factors when we study China's economic growth. Figure 1(b) shows the growth rate of China's carbon dioxide emissions and energy consumption relatively to 1999 in the 1999-2012 periods. The figure shows that China's carbon dioxide emissions and energy consumption growth is almost at the same speed, which means that greenhouse gas emissions and energy consumption have a great relationship. Figure 1(c) reports the world's carbon dioxide emissions from 1980 to 2010, and 
(a) GDP and the inputs growth of China
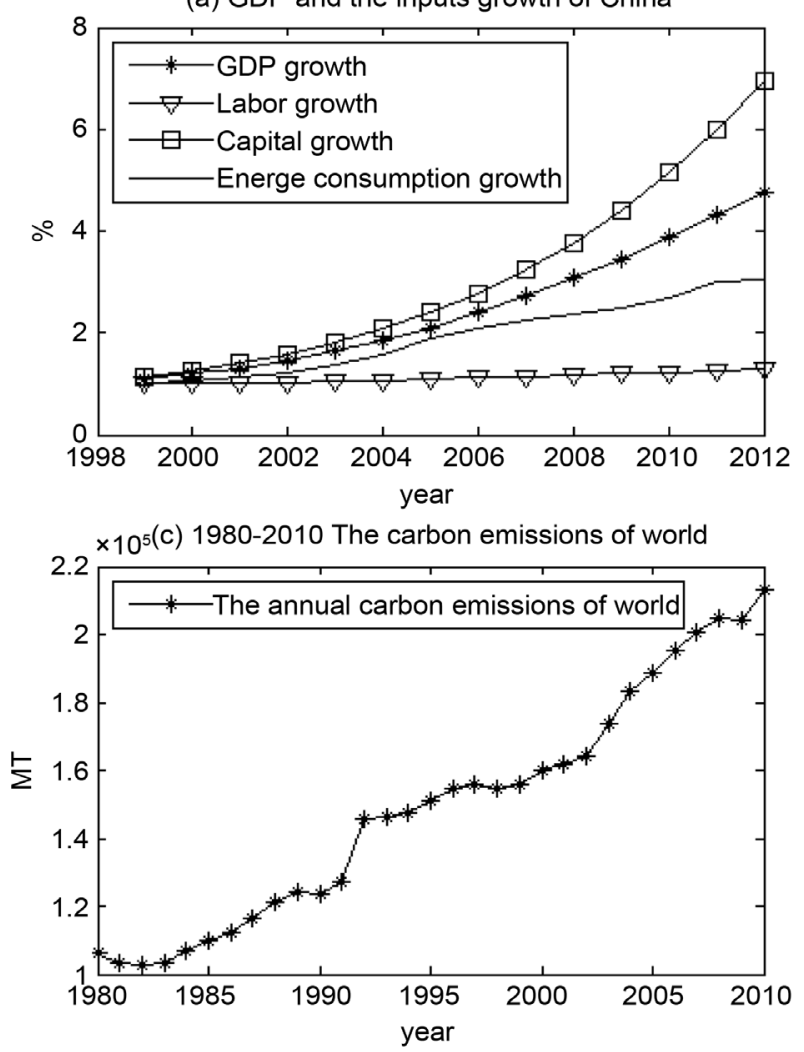

(b) Carbon emission and Energy consumption growth

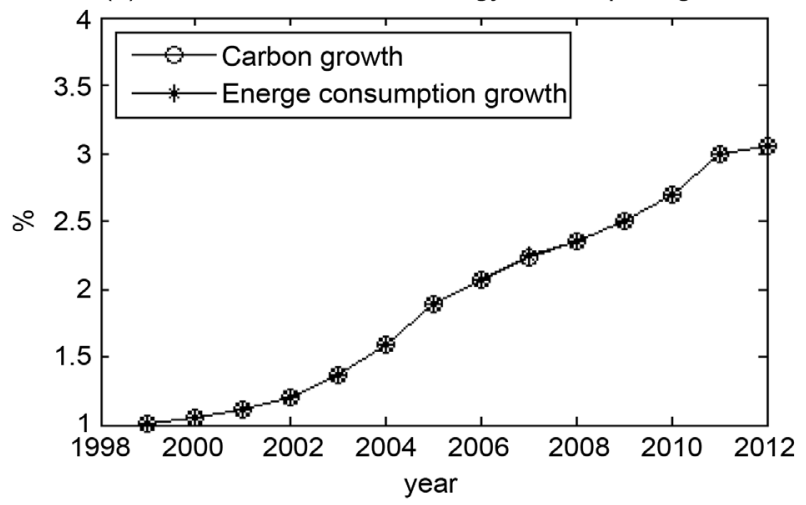

(d) China carbon emissions accounting for the proportion of the world

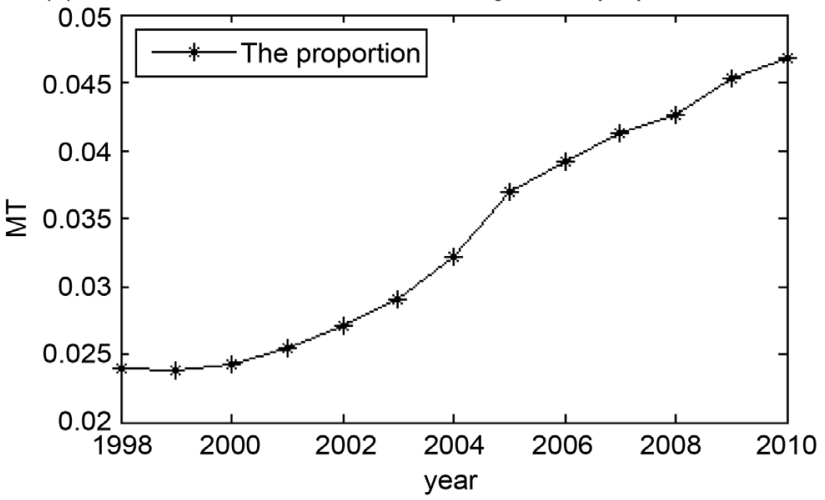

Figure 1. Energy input, carbon emissions and economic growth in China.

shows that with the increase of human activities greenhouse gas emissions increased significantly, carbon dioxide emissions of 90 years in the world is 1.5 times to the emissions at the beginning 80 years. Figure 1(d) reports proportion of the China's carbon dioxide emissions to the world. It is clear that as China's great economic growth in recent years, the increase of energy inputs leads the greenhouse gases to rise from $2.4 \%$ of 1999 to $4.7 \%$ of 2010 which is about twice amount. It means that China undertakes a large environmental cost today. China's growth should be sustainable and coordinate with environment. So we need to take environmental regulation and energy inputs into account.

The traditional economic growth theory, however, only focus on GDP and other "good" output rather than the "bad" output such as the carbon dioxide produced by enterprise production activities, and only use economic interest to evaluate the enterprise's production efficiency, resulting in bias when we measure the regional economic development. Now, China's economy is in the stage of economic transition and the slowdown in growth, which means that the economic development should depend on "quality and efficiency" rather than "quantity". Therefore, to evaluate China's economic growth, it is necessary to take energy inputs and factors of environmental control into the production function, in which the energy structure, industrial structure and other factors should be considered also, thus on point of the quality growth we are able to investigate the spatial effect of China's economic growth. 
The rest of this paper is organized as follows. The next section features a brief review of the relevant literature about the sources of economic growth. The theoretical methods, which contain the Biennial Malmquist-Luenberger ( $B M L)$ productivity index, Spatial Durbin Model (SDM) and its relevant test are introduced in Section 3. Section 4 discusses the data and empirical results, and analyzes the spatial difference containing the dynamics of economic growth and convergence. Finally, Section 5 presents the conclusions and policy implications derived from the study.

\section{Literature Review}

Researching the related factors which affect China's economic growth and convergence is crucial to identify the developmental difference of different region, and has important significance to regional development balance in China. On the discussion of China's economic high-speed growth, Chow et al. [1] and other scholars gradually reached a consensus: It is the TFP drive China's economic growth. Park et al. [2] thinks that $50 \%$ of GDP growth is due to the improvement of TFP. Liu and Zhang [3] hold a opinion that the promoting effect results from the economic structure change to TFP is reducing, and the role of technological progress is more and more important (see also Yao [4]). $\mathrm{Li}$ and $\mathrm{Lu}$ [5] present a view that China's manufacturing productivity growth is mainly derived from internal productivity, while the influence of industrial structure is smaller relatively. Mitze and Ozyurt's [6] empirical results show that FDI can promote the improvement of productivity. Yao [7], besides, propose the important channel, that making factors more circulating, to improve TFP. Others researches (see, e.g., [8]) focus on the human capital and foreign trade aspect.

Accordingly, many scholars do a lot of empirical research in the convergence problem of economy. Mankiw [9] hold a view that it is the convergence of TFP provides the possibility to assist underdeveloped regions to catch up developed area. This view is accepted and developed by later scholars. Bo and Liang [10] believes that divergence exists in the western region, and Liu [11] think that China's urbanization level also affects the production efficiency improvement in backward areas. Liu [12], besides, use the ML index method and finds the convergence of energy efficiency in China's east and Central region. Ma [13] found the FDI, ownership structure, and human capital affect China's productivity convergence. Lemoine [14] thinks the capital and the technology has the trend to transfer from the developed coastal areas to the inland areas, and further promote industrial productivity convergence.

For the computational development of the Malmquist-Luenberger (ML) index, Caves et al. [15] introduced the earliest type of the ML index. Ray and Desli [16] provides the $\mathrm{RD}$ decomposition, which decompose the change of productivity change into 3 factor, to analyze the scale efficiency change of production units. Chung et al. [17], considering the existence of the undesired output, introduces the directional distance function (DDF) in calculation of ML index. Shestalova [18] relaxes assumption that constant returns to scale. In the follow, Chen [19] proposes the non-radial DEA model, and Pastor and Lovell [20] consider the technology retrogression in the measure of productivity. 
Pastor et al. [21] optimizes the solving way, and put forward the $B M L$ index, which is use in environmental constraint by Aparicio et al. [22].

Through the above literature, we can find that: Part of the literatures assume that the efficiency of different areas in China will tend to the same level, ignoring the regional heterogeneity (see e.g., Zou et al. [23]). Even though some researches notice the difference of convergence in different regions, they disregard the spatial effect in regions when they study the convergence (see, e.g., Li [24]). Because of the pollution cost of backward area, which is lower than the developed regions (Kaneko et al., [25]). Besides, the industry with high energy consumption and high emissions of pollution tend to transfer to backward district. It would restrict the improvement of total factor productivity. Most of the literatures, however, only use the traditional input-output function, which ignore the environment and energy, to compute the production efficiency, existing a certain amount of biases in empirical results. Although Managi and Kaneko [26], Watanabe and Tanaka [27] consider environmental regulation when they measure TFP, they haven't considered the spatial impact in the convergence.

Contra posing the limitations of above study, this paper tries to lucubrate from the following three aspects: 1) combine the data envelopment analysis (DEA) and directional distance function, and use the $B M L$ index to measure Chinese $T F P$, considering the carbon emission constraints and energy inputs; 2) introduce the spatial econometrics to index decomposition theory, analyze the total effect, direct effect and indirect effect of influential elements in different regions; 3) utilize Spatial Durbin Model to study the development convergence in different region, and try to explain the effect of different factors to the TFP convergence.

\section{Methods}

\subsection{Measurement and Decomposition of TFP}

In this section, we use the data envelopment analysis (DEA), a non-parametric estimation method, to decompose the TFP. DEA method is proposed by Charnes [28], which is based on a production frontier (effective frontier) structured by input-output data, to evaluate the relative efficiency of each decision making unit (DMU), without a specific function. According to the different assumptions, through the linear programming form, we can find an envelope of all actual production at the minimum convex cone or convex polyhedron. And then, according to the distance between the DMU and the production boundary, the input-output efficiency of each DMU will be evaluated. As the method do not need to define the form of the production function, and also not have to assume the distribution of the parameters, it is widely used in the study of economic growth of different regions. However, the traditional productivity measure takes labor and capital as inputs, and GDP as an output, meanwhile the energy and the factors of environment, which are closely related to the sustainable development are seldom considered. In fact, energy and environment are closely related to China's economic growth, and China's economic growth depends on high investment, high energy consumption, and high pollution. So this paper puts energy into the traditional input- 
output function as an input variable, and the region's greenhouse gas emissions as a not-expected output in order to scale the energy consumption and environment cost.

The regional production technology level is reflected in the productivity and the production frontier of the input-output function. That is the set of the maximum of the expected output and the minimum of not-expected output by the given inputs. Taking into account the importance of energy and environment in the production stage of enterprises, it is assumed that the production set in period $t$ is:

$$
S(t)=\left\{\left(L^{t}, K^{t}, E^{t}, Y^{t}, C^{t}\right):\left(L^{t}, K^{t}, E^{t}\right) \text { can produce }\left(Y^{t}, C^{t}\right)\right\}
$$

where the variables $L, K, E \in R_{+}$denote an input vector for labor, capital and energy, respectively; $Y \in R_{+}$denotes gross regional product (GRP) as the desirable or good output; and $\mathrm{C} \in R_{+}$represents $\mathrm{CO}_{2}$ emissions as the undesirable or bad output. In order to use production set $S(t)$ to describe environmental technology, two axioms are introduced here. The first one is called null-jointness or by-product axiom: A firm will have no bad output, if it does not produce a good output. In other word, a good output will certainly accompany a bad output; The second one is the weak disposability of inputs and outputs axiom: it indicates that if the inputs $(L, K, E)$ can produce the greatest outputs $(Y, C)$, and then it is feasible to increase these outputs proportionally by $\theta$ where $\left(Y^{\prime}, C^{\prime}\right)=(\theta Y, \theta C)$ and $0 \leq \theta \leq 1$. This axiom also reveals that it is costly to dispose of an undesirable output with the environmental regulation. Therefore, according to the above axioms, production sets $S(t)$ can be further expressed as:

$$
S(t)=\left\{(Y, C): \sum_{i=1}^{I} z_{i}^{t} Y_{i}^{t} \geq Y, \sum_{i=1}^{I} z_{i}^{t} C_{i}^{t}=C, \sum_{i=1}^{I} z_{i}^{t} L_{i}^{t} \leq L, \sum_{i=1}^{I} z_{i}^{t} K_{i}^{t} \leq K, \sum_{i=1}^{I} z_{i}^{t} E_{i}^{t} \leq E, z_{i}^{t} \geq 0\right\}
$$

where $i=1,2, \cdots, I$ denotes the number of decision making unit (DMU); $Z_{i}$ is the weight assigned to each DMU when constructing the production possibilities frontier; and $Z_{i}>0$ means that the production technology exhibits constant returns-to-scale (CRS). In addition, the output set at the time period $t+1$ can be similarly defined as $S(t+1)$.

The standard measure to a region's efficiency is the max improvement range for the reduction of inputs and increase of outputs. Chambers et al. [29] constructed the DDF, which measures the distance from the observation to the production boundary. The directional output distance function provides a good method for modeling economic and environmental performances. Further, this function at time period $t$ with the biennial technology is defined as

$$
\boldsymbol{D}_{0}^{B}\left(L^{t}, K^{t}, E^{t}, Y^{t}, C^{t} ; g\right)=\sup \left\{\eta:\left(Y^{t}, C^{t}\right)+\eta g \in S(B)\right\}
$$

where $g\left(g_{y},-g_{c}\right)$ is a direction vector, and $\overrightarrow{D_{0}^{B}}\left(L^{t}, K^{t}, E^{t}, Y^{t}, C^{t} ; g\right)$ measures the maximum proportional expansion of both desirable and undesirable outputs $\left(Y^{t}, C^{t}\right)$, given the input vector $\left(L^{t}, K^{t}, E^{t}\right)$ and $g$ is the optimal direction of the output combination adjusted to biennial production frontier. Following the decomposition method of Du and Wang [30], the growth of TFP can be depicted by $B M L$ index, and further decomposed into $E F F$ and $T C$ : 


$$
\begin{aligned}
B M L= & \frac{1+\boldsymbol{D}_{0}^{B}\left(L^{t}, K^{t}, E^{t}, Y^{t}, C^{t} ; g^{t}\right)}{1+\boldsymbol{D}_{0}^{B}\left(L^{t+1}, K^{t+1}, E^{t+1}, Y^{t+1}, C^{t+1} ; g^{t+1}\right)} \\
= & {\left[\frac{1+\boldsymbol{D}_{0}^{t}\left(L^{t}, K^{t}, E^{t}, Y^{t}, C^{t} ; g^{t}\right)}{1+\boldsymbol{D}_{0}^{t+1}\left(L^{t+1}, K^{t+1}, E^{t+1}, Y^{t+1}, C^{t+1} ; g^{t+1}\right)}\right] } \\
& \times\left[\frac{1+\boldsymbol{D}_{0}^{B}\left(L^{t}, K^{t}, E^{t}, Y^{t}, C^{t} ; g^{t}\right)}{1+\boldsymbol{D}_{0}^{t}\left(L^{t}, K^{t}, E^{t}, Y^{t}, C^{t} ; g^{t}\right)} \times \frac{1+\boldsymbol{D}_{0}^{t+1}\left(L^{t+1}, K^{t+1}, E^{t+1}, Y^{t+1}, C^{t+1} ; g^{t+1}\right)}{1+\boldsymbol{D}_{0}^{B}\left(L^{t+1}, K^{t+1}, E^{t+1}, Y^{t+1}, C^{t+1} ; g^{t+1}\right)}\right] \\
= & E F F \times T C=T F P
\end{aligned}
$$

Equation (4) shows that the $B M L$ index is decomposed into two components: technical efficiency change $(E F F)$ and technological change (TC). The first component, $E F F$, which indicates a catching-up effect and measures the change in the distance towards the best practice frontier by given the technology. The second component, $T C$, which measures the technological progress, captures the extent, to which the production frontier shifts from period $t$ to $t+1$ by taking the biennial technology as a reference. Because the biennial technology is defined as the convex hull of the period $t$ and $t+1$ technologies, we do not need to take the arithmetic mean or geometric mean when defining the $B M L$ index.

Where $\overrightarrow{D_{0}^{B}}\left(L^{t}, K^{t}, E^{t}, Y^{t}, C^{t} ; g\right)$ is the efficiency of period $t$ evaluated by using the production frontier with data the period $t, t+1$. According to a DEA-type linear programming approach, we can calculate the value of the TFP, EFF and TC by solving the following LP problem:

$$
\begin{gathered}
D_{0}^{B}\left(L^{t}, K^{t}, E^{t}, Y^{t}, C^{t} ; g\right)=\max \eta \\
\sum_{i}^{I} \lambda_{i}^{t} y_{i}^{t}+\sum_{i}^{I} \lambda_{i}^{t+1} y_{i}^{t+1} \geq y_{i}^{t}(1+\eta) ; \sum_{i}^{I} \lambda_{i}^{t} L_{i}^{t+1}+\sum_{i}^{I} \lambda_{i}^{t} L_{i}^{t+1} \leq L_{i}^{t} \\
\text { s.t. } \sum_{i}^{I} \lambda_{i}^{t} K_{i}^{t}+\sum_{i}^{I} \lambda_{i}^{t+1} K_{i}^{t+1} \leq K_{i}^{t} ; \quad \sum_{i}^{I} \lambda_{i}^{t} E_{i}^{t}+\sum_{i}^{I} \lambda_{i}^{t+1} E_{i}^{t+1} \leq E_{i}^{t} \\
\sum_{i}^{I} \lambda_{i}^{t} C_{i}^{t}+\sum_{i}^{I} \lambda_{i}^{t+1} C_{i}^{t+1}=C_{i}^{t}(1-\eta) ; \lambda_{i}^{t}, \lambda_{i}^{t+1}>0
\end{gathered}
$$

\subsection{Conditional Convergence Analysis}

Conditional convergence (Barro [31]) refers to the control of the technical level, the energy structure and other factors, the productivity will eventually converge to their steady-state in the region, the conditional convergence model is as follows:

$$
\ln \left(\frac{T F P_{i, t+1}}{T F P_{i, t}}\right)=\alpha+\beta_{i} \ln \left(T F P_{i, t}\right)+\sum_{j=1}^{n} \lambda_{j} X_{i, j, t}+\varepsilon_{i, t}
$$

where $T F P_{i, t}, T F P_{i, t+1}$ denote the TFP of region $i$ in the period of $t$ and $t+1$ respectively. $X_{i, j, t}$ denotes the control variable $j$ in the region $i . \lambda_{i}$ and $\beta$ is the variable coefficient, and the $\varepsilon_{i, t}$ is the residual. If $\beta<0$, there is a conditional convergence. That is, the rate of increase in productivity is inversely proportional to the initial level, accompanying the catch-up effect in backward areas, and the smaller the beta is, simul- 
taneously, the faster the convergence rate is. Further, Equation (6) can be changed to:

$$
\ln \left(T F P_{i, t+1}\right)=\alpha+\left(1+\beta_{i}\right) \ln \left(T F P_{i, t}\right)+\sum_{j=1}^{n} \lambda_{j} X_{i, j, t}+\varepsilon_{i, t}
$$

In this equation, if the explanatory coefficient is significant we can achieve two objectives. On the one hand, the variable $X_{i, j, t}$ is used as a control variable to examine the convergence of productivity, basing the hypothesis of conditional convergence. On the other hand, the control variables, according to the definition of efficiency, are also the independent variables to reveal the effects of the convergence. Meanwhile the convergence of $E F F$ and $T C$ can be similarly defined.

\subsection{Spatial Durbin Model}

Anselinet et al. [32] points out that the spatial panel model includes spatial lagged dependent variables or spatial auto regression processes when there is spatial relationship between the observed individuals, corresponding the spatial lag model (SAR) and spatial error model (SEM), respectively. Pace and LeSage [33] construct a more extensive model, Spatial Durbin Model, which contains both the dependent variable and independent variables. As the change of TFP, EFF and $T C$ will be influenced by their own size of the population, the level of capital, openness and etc., and will also be affected by spillover effect from other regions, the paper takes the TFP, EFF and TC as the dependent variable respectively, and use the SDM to measure the spatial effects of different regions with lagged dependent variables and independent variables. The equation is given by:

$$
\begin{aligned}
& \operatorname{TFP}_{t}=\rho W T F P_{t}+\left[\operatorname{TFP}_{t-1}, X\right] \beta+W\left[T F P_{t-1}, X\right] \theta+\alpha \tau_{n}+\varepsilon \\
& \varepsilon \sim N\left(0, \sigma^{2} I_{n}\right)
\end{aligned}
$$

where $W, X, \rho, I, \tau_{n}$ represent the spatial weight matrix, independent variable matrix, spatial correlation coefficient, Unit matrix of $\mathrm{N}^{\star} 1$ and Individual intercept vector, respectively. $\alpha, \beta, \theta, \rho$ are parameter matrices. $\sigma$ follows the normal distribution of multiple variables. Besides, as regional technological innovation activities are largely concentrated in the provincial capital or Central city, this paper establishes a space inverse distance weight matrix, which describes the inter-provincial spatial correlation, with the geographic distance between the provincial capital cities to study the characteristics of regional convergence. The equation can be solved as following:

$$
\begin{gathered}
T F P_{t}=S_{\text {TFP }}(W) T F P_{t-1}+\sum_{r=1}^{k} S_{r}(W) x_{r}+V(W) \alpha \tau_{n}+V(W) \varepsilon \\
V(W)=\left(I_{n}-\rho W\right)^{-1}=I_{n}+\rho W+\rho^{2} W^{2}+\rho^{3} W^{3}+\cdots \\
S_{r}(W)=V(W) \times\left(I_{n} \beta_{r}+W \theta_{r}\right) \\
S_{T F P}(W)=V(W) \times\left(I_{n} \beta_{T F P}+W \theta_{r}\right)
\end{gathered}
$$

Based on the view of Pace and LeSage [33], the elements of the matrix $S_{r}(W)$ are decomposed into average direct effect, average total effect, and average overall effect of 
the independent variables. In order to explain the effect, the matrix will be further expanded, and the effect of the independent $r$ on the dependent variable can be described as:

$$
\left(\begin{array}{c}
y_{1} \\
y_{2} \\
\vdots \\
y_{3}
\end{array}\right)=\sum_{r=1}^{k}\left(\begin{array}{cccc}
S_{r}(W)_{11} & S_{r}(W)_{12} & \cdots & S_{r}(W)_{1 n} \\
S_{r}(W)_{21} & S_{r}(W)_{22} & \cdots & S_{r}(W)_{2 n} \\
\vdots & \vdots & \ddots & \vdots \\
S_{r}(W)_{n 1} & S_{r}(W)_{n 2} & \cdots & S_{r}(W)_{n n}
\end{array}\right)\left(\begin{array}{c}
x_{1 r} \\
x_{2 r} \\
\vdots \\
x_{n r}
\end{array}\right)
$$

Among them, $\left(S_{r}(W)_{j 1}, S_{r}(W)_{j 2}, \cdots, S_{r}(W)_{j n}\right)$ is the total influence on the dependent variable of region $j$ by explanatory variables from all regions; Meanwhile, the $\sum\left(S_{r}(W)_{1 j}, S_{r}(W)_{2 j}, \cdots, S_{r}(W)_{3 j}\right)^{\mathrm{T}} \cdot X_{j r}$ is the total effect from explanatory variable $r$ of area $; \operatorname{Tr}\left(S_{r}(W)\right)$ is the total effect on the dependent variable from its own explanatory variables. And then average spillover effect can be calculated by the average level of total effect and average effect directly as following:

$$
\text { average spillover effect }=\text { average total effect }- \text { average direct effect }
$$

Equation (14) provides a way to measure the spatial impact of regions.

\section{Data and Empirical Results}

\subsection{Data}

This study considers 30 provinces in China as study subjects. Data for 15 years between 1999 and 2012 are collected in the empirical analysis. In the productivity measure, the inputs variables (labor, capital stock and energy consumption), and outputs variables (GRP and $\mathrm{CO}_{2}$ emissions) are considered in each region. We also use the independent variable (technology patents, energy structure, ownership structure, industrial structure, urbanization level, foreign direct investment) to measure the spatial effect on productivity.

The data on labor input and GRP are obtained directly from the China Statistical Yearbook [34]. Labor input is measured by the number of employees. Data for total energy consumption are collected from the China Energy Statistical Yearbook [35]. Energy consumption consists of coal, washing coal, coke, oven gas, oil, gasoline, diesel, fuel, kerosene, liquefied petroleum, natural gas, refinery gas and others. The physical quantity of all energy is converted to a standard amount. There are no official data available for the capital stock of Chinese provinces. Following the perpetual inventory method, the capital stock for each province in year $t$ is calculated by Perpetual inventory method ( $\mathrm{Wu}[36])$. To estimate the capital stock, we need to determine the initial capital stock and depreciation rate. Due to the capital stock from 1900 to 1952 was completely depreciated, we assume that the initial capital stock is 0 in 1900, and the annual data from 2012 to 1952 in all provinces are obtained by the Yearbook to calculate the depreciation rate of different provinces. Assume that the investment growth rate is $\gamma$, the time series of investment can be approximated by $I(t)=I(0) e^{\gamma t}$. Then the initial capital stock can be expressed by the following:

$$
K(0)=\int_{-\infty}^{0} I(t) \mathrm{d} t=I(0) \mathrm{e}^{\gamma} / \gamma
$$


And $I(0)$ and $\gamma$ can be found by the logarithm regression of the investment sequences in 1952-2012 period:

$$
\ln I(t)=\ln I(0)+\gamma t, t=1, \cdots, 61
$$

Therefore, the capital stock of $t$ can be obtained by the following formula:

$$
K(t)=(1-\delta) K(t-1)+I(t), t=2, \cdots, 61
$$

Using the Equation (16), we adopt different depreciation rates and capital stocks for each province.

The actual provincial $\mathrm{CO}_{2}$ emissions cannot be obtained directly from the official data. $\mathrm{CO}_{2}$ emissions mainly result from fossil energy consumption. The publication Guidelines for National Greenhouse Gas Inventories [37] provides a reference formula to estimate $\mathrm{CO}_{2}$ emissions. Following this method, we can use provincial-level energy consumption to forecast $\mathrm{CO}_{2}$ emissions in each province. The estimation's equation is given by:

$$
C O_{2}=\sum_{j=1}^{n} C O_{2, j}=\sum_{j=1}^{n} E_{j} \times N C V_{j} \times C E F_{j} \times C O F_{j} \times(44 / 12)
$$

where $j$ represents the type of energy; $E$ represents a variety of energy consumption; and $N C V, C E F$ and $C O F$ represent the average low calorific values of energy, carbon emission coefficients and the carbon oxidation factor, respectively. For control variables, the level of technology is represented by the number of patent applications, the energy structure of coal consumption accounts for the proportion of total energy consumption. The industrial output value accounts of the proportion of industrial structure and the proportion of urban population accounts for the second total industrial output.

We also study the influence of the innovation activity, energy structure, ownership structure, industrial structure, regional openness, and urban scale on economic growth. The innovation activity is represented by the number of patent applications, and the energy structure is expressed as the proportion of raw-coal consumption in total energy consumption. Besides, the ownership structure is presented by the ratio of the stateowned factories production to factories production; The industrial structure is denoted by the percentage of value-added of industry in total value-added. The level of urbanization is expressed by the proportion of the city population in total population. The degree of economic openness, in addition, is represented by FDI.

Table 1 shows the summary statistics of all variables. All nominal variables are deflated to real variables by using a price index for the year 2000 .

\subsection{Empirical Results}

By decomposing the growth of the 30 provinces of China, we get the ratio of the total factor productivity, technical efficiency and technological progress of the provinces in 1999 to 2012.

Table 2 shows that EFF has a downward trend in the country. From regional aspect, 
Table 1. Summary statistics of variables, 1999-2012.

\begin{tabular}{cccccc}
\hline & Mean & S.D. & Max & Min & Obs \\
\hline Gross regional product (100 million CNY) & 6620.05 & 6671.37 & $42,860.33$ & 223.88 & 450 \\
Carbon dioxide emissions (10,000 tonnes) & $23,104.14$ & $18,408.16$ & $10,667.02$ & 892.85 & 450 \\
Labor (10,000 persons) & 2304.32 & 1525.40 & 6288.00 & 230.4 & 450 \\
Capital stock (100 million CNY) & $18,642.28$ & $17,905.50$ & $110,064.98$ & 953.54 & 450 \\
Energy consumption (10,000 tones) & 8797.00 & 6970.46 & 40631.00 & 384.48 & 450 \\
Technology (item) & $10,845.60$ & $25,738.52$ & $269,944.00$ & 62 & 450 \\
Energy structure (\%) & 71.23 & 19.63 & 158.57 & 24.22 & 450 \\
Ownership structure (\%) & 44.18 & 21.81 & 116.08 & 7.78 & 450 \\
Industrial structure (\%) & 40.26 & 11.38 & 65.99 & 12.66 & 450 \\
Urbanization level (\%) & 34.61 & 16.14 & 89.76 & 14.25 & 450 \\
FDI (100 million) & 216.1275 & 292.95 & 1511.1828 & 1.0621 & 450 \\
\hline
\end{tabular}

Table 2. Decomposition indexes of economic growth between 1999 and 2012.

\begin{tabular}{cccccccc}
\hline Provinces & $E F F$ & $T C$ & $T F P$ & Provinces & $E F F$ & $T C$ & $T F P$ \\
\hline Ningxia & 0.9047 & 2.5458 & 2.3031 & Guizhou & 1.0347 & 1.5719 & 1.6264 \\
Jiangsu & 1.0020 & 2.1309 & 2.1350 & Gansu & 0.9955 & 1.6217 & 1.6143 \\
Shaanxi & 0.9723 & 2.0326 & 1.9763 & Hainan & 0.8851 & 1.8102 & 1.6022 \\
Xingjiang & 0.8783 & 2.1757 & 1.9110 & Henan & 0.9486 & 1.6786 & 1.5923 \\
Fujian & 0.8745 & 2.1730 & 1.9004 & Guangxi & 0.8394 & 1.8913 & 1.5877 \\
Qinghai & 0.9781 & 1.9329 & 1.8905 & Hunan & 1.0049 & 1.5712 & 1.5790 \\
Zhejiang & 0.9246 & 2.0366 & 1.8832 & Hebei & 0.8814 & 1.7824 & 1.5710 \\
Yunnan & 0.9384 & 1.8763 & 1.7607 & Tianjin & 1.2052 & 1.3008 & 1.5677 \\
Shandong & 0.9022 & 1.9403 & 1.7505 & Shanghai & 1.0000 & 1.5420 & 1.5420 \\
Chongqing & 1.0582 & 1.6083 & 1.7019 & Guangdong & 1.0000 & 1.5111 & 1.5111 \\
Sichuan & 1.0736 & 1.5745 & 1.6904 & Jilin & 0.9097 & 1.3635 & 1.2403 \\
Anhui & 0.9878 & 1.7076 & 1.6868 & Liaoning & 0.9141 & 0.8152 & 0.7451 \\
Beijing & 1.0247 & 1.6299 & 1.6701 & Heilongjiang & 1.4271 & 0.3764 & 0.5371 \\
Jiangxi & 0.9794 & 1.6900 & 1.6551 & Inner Mongolia & 1.2146 & 0.0740 & 0.0898 \\
Hubei & 1.0131 & 1.6127 & 1.6338 & Shanxi & 0.5903 & 0.1342 & 0.0792 \\
Countrywide & 0.9787 & 1.5904 & 1.5345 & Central China & 0.9811 & 1.7263 & 1.6462 \\
Northeast China & 1.0836 & 0.8517 & 0.8408 & West China & 0.9207 & 1.3990 & 1.3710 \\
East China & 0.9700 & 1.7857 & 1.7133 & & & & \\
\hline
\end{tabular}

Notes: The relative changes of $T F P, T C$ and $E F F$ were reported in the table in 2012 to 1999, and Regional EFF, TFP, $T C$ change is the average value.

EFF has improved in the northeast while showed a downward trend in the eastern, central, western and other regions; From provincial aspect, the EFF of Beijing, Tianjin, Inner Mongolia, Heilongjiang, Jiangsu, Hubei, Chongqing, Sichuan, Guizhou and Hunan (ten provinces) has improved and Heilongjiang's EFF made fastest progress in the 
period of 1999-2012; Guangdong and Shanghai's EFF, besides, have not change in the period. Except the above provinces, the $E F F$ of other provinces has descended especially the Shanxi.

$T C$ has a rising trend in the country. From regional level, $T C$ has declined in the northeast which exists the technical retrogression, but has a rising trend in the eastern, central and western areas; From the province level, Liaoning, Heilongjiang, Shanxi and Inner Mongolia (four provinces) appear technology retrogression phenomenon; Among them, Shanxi and Inner Mongolia's technology retrogress most seriously; Jiangsu, Zhejiang, Fujian, Shaanxi, Ningxia and Xinjiang make a great progress in technology, mainly concentrating in the Eastern region.

The TFP has an upward trend which is consistent with the $T C$ in the regional aspect. Similarly, only Liaoning, Heilongjiang, Shanxi and Inner Mongolia, from the province level, have a phenomenon of productivity degradation. EFF and TC show the fact that Shanxi now has the lowest productivity in China. From 1999 to 2012, the technical efficiency of our country had been decreasing. But because the positive effect of the technology improvement is greater than the negative effect of the technical efficiency decline, the total factor productivity in China is increasing, and we can draw a conclusion that the total factor productivity improvement in the period of our country is mainly due to the improvement of technology.

\subsection{Convergence Analysis of EFF and TC}

This paper determines the type of fixed effects by the LR test of the joint significance of space and time, and then make LM test of spatial lag and spatial error (including robust LM inspection) basing the results of LR test. Having compared with the results of Wald test, we use the spatial model (SDM) to carry out the empirical analysis. The relevant test results are shown in Appendix Tables A1-A3. Lesage and Pace [33] have pointed out the spillover effects measured by the point estimation method are biased, and they proposed that the impact of the change of variables in different model settings can be explained by the method of solving partial differential equations. Then the regression results can be further divided into total effect, direct effect and indirect effect.

Table 3 shows that the EFF is convergent in China, indicating that China's technical efficiency will be at a steady growth pace in a long term. From regional perspective, the $E F F$ is convergent in northeast, east and central region except the west. Table 4 indicates that the $T C$ in the east and central region is convergent except northeast and west, and shows convergence in China. This shows that there are some differences in regional technical improvement, and some regional imbalance in the technology development. From the coefficient of variables, we can get the following results.

\subsubsection{Innovation Activity}

Innovation activity has significantly positive effect to $E F F$ in central, eastern regions and nationwide, showing that the innovation of the technology has promoted the convergence of EFF; For the whole country, central and northeast region, the promotion of the innovation activity is concentrated in the spillover effect. In addition, the total effect 
Table 3. Spatial Durbin model with spatial random effects of EFF.

\begin{tabular}{cccccc}
\hline Variable & Countrywide & Northeast & East & West & Central \\
\hline EFF & $-0.0635^{* *}$ & $-0.3022^{* * *}$ & $-0.1351^{* *}$ & -0.0122 & $-0.0648^{* * *}$ \\
& $(0.0260)$ & $(0.0350)$ & $(0.0610)$ & $(0.0560)$ & $(0.0140)$ \\
Patent & $0.0367^{* *}$ & 0.0018 & $0.0147^{* * *}$ & 0.0169 & $0.2158^{* *}$ \\
& $(0.0150)$ & $(0.0080)$ & $(0.0030)$ & $(0.0160)$ & $(0.1070)$ \\
Energy & 0.0434 & -0.0771 & 0.0138 & -0.002 & $0.2788^{* * *}$ \\
& $(0.0280)$ & $(0.1770)$ & $(0.0200)$ & $(0.0510)$ & $(0.0850)$ \\
Ownership & -0.0794 & -0.0791 & 0.1358 & -0.0778 & $-0.1882^{* *}$ \\
& $(0.0720)$ & $(0.0750)$ & $(0.1070)$ & $(0.1670)$ & $(0.0790)$ \\
Industrial & $-0.8811^{* *}$ & $-0.1739^{* *}$ & -0.0458 & $-0.8161^{*}$ & $-4.8184^{*}$ \\
& $(0.4200)$ & $(0.0770)$ & $(0.3600)$ & $(0.4610)$ & $(2.5200)$ \\
Urbanization & 0.0984 & $-1.2804^{*}$ & -0.0709 & 0.3428 & 0.9735 \\
& $(0.3860)$ & $(0.7370)$ & $(0.1400)$ & $(0.4170)$ & $(0.7700)$ \\
FDI & -0.0091 & 0.0153 & -0.0091 & 0.013 & 0.0491 \\
& $(0.0280)$ & $(0.0120)$ & $(0.0160)$ & $(0.0310)$ & $(0.0430)$ \\
$\mathrm{N}$ & 390 & 39 & 130 & 143 & 78 \\
& 0.0488 & 0.5857 & 0.3595 & 0.0857 & 0.1509 \\
\hline & & & &
\end{tabular}

Table 4. Spatial Durbin model with spatial fixed effects of $T C$.

\begin{tabular}{cccccc}
\hline Variable & Countrywide & Northeast & East & West & Central \\
\hline$T C_{t-1}$ & $0.3349^{* * *}$ & -0.066 & $-0.2548^{* * *}$ & 0.1803 & $0.1940^{* * *}$ \\
& $(0.0620)$ & $(0.1400)$ & $(0.0900)$ & $(0.1140)$ & $(0.0660)$ \\
Patent & $-0.0368^{* * *}$ & -0.0049 & $-0.0462^{* * *}$ & -0.0035 & -0.0029 \\
& $(0.0120)$ & $(0.0170)$ & $(0.0110)$ & $(0.0260)$ & $(0.0550)$ \\
Energy & -0.1188 & $-0.1677^{* * *}$ & $0.1050^{* * *}$ & -0.0323 & $-0.6073^{* * *}$ \\
& $(0.0750)$ & $(0.0390)$ & $(0.0380)$ & $(0.1180)$ & $(0.0920)$ \\
Ownership & 0.0842 & $-0.1751^{* * *}$ & -0.0152 & -0.1185 & -0.0793 \\
& $(0.0970)$ & $(0.0460)$ & $(0.1790)$ & $(0.2460)$ & $(0.0970)$ \\
Industrial & 0.9226 & $-1.6138^{* * *}$ & $0.9090^{* *}$ & 0.3999 & 0.1287 \\
& $(0.5660)$ & $(0.1270)$ & $(0.4260)$ & $(0.9110)$ & $(1.2610)$ \\
Urbanization & 0.158 & $1.5460^{*}$ & 0.3889 & -0.5331 & 0.169 \\
& $(0.4640)$ & $(0.8210)$ & $(0.4510)$ & $(0.6920)$ & $(0.5650)$ \\
FDI & -0.022 & -0.0085 & -0.018 & -0.0462 & -0.0108 \\
& $(0.0320)$ & $(0.0100)$ & $(0.0130)$ & $(0.0470)$ & $(0.0310)$ \\
R2 & 390 & 39 & 130 & 143 & 78 \\
\hline & 0.4135 & 0.9644 & 0.3024 & 0.4711 & 0.929 \\
\hline
\end{tabular}

Notes: ${ }^{*},{ }^{* *},{ }^{* *}$ denote $\mathrm{p}<0.1, \mathrm{p}<0.05$ and $\mathrm{p}<0.01$ respectively; Here only report the total effect of the regression results, the direct effect and spillover effect on EFF is shown in Appendix Table A4 and Table A5, and the direct effect and spillover effect on $T C$ is shown in Appendix Table A6 and Table A7. 
to the central region is biggest, showing strong positive externality. It means that the innovation activity has the largest promotion on the convergence of $E F F$ to the central region. In the aspect of $T C$, the total effect of innovation activity in the nationwide and the eastern region is positive, which indicates that the innovation activity has made the $T C$ divergence in east, and further made $T C$ divergence in nationwide. And the coefficient in the $T C$ indicates that the positive impact of innovation activity is based on positive externalities in middle region and northeast while is based on direct effect on western region. This also indicates that the innovation activity can promote the improvement of the $T C$ in the west, but it will not promote the regional convergence.

\subsubsection{Energy Structure}

In the aspect of $E F F$, the energy structure only has a positive effect on the central convergence by the direct effect. This shows that central region can use coal to achieve the "catch-up" effect in technical efficiency while the energy consumption structure adjustment has little such effect in other regions. Energy structure is not significant on the total effect of $T C$ in west, which shows that the energy structure does not promote technological progress in the West. Besides, the energy structure has positive total effect on east and negative total effect on northeast and middle area, which means that the energy structure not merely promote the convergence of the eastern technology, but also expand the difference in northeast and central region. It can be indicated that there is a heterogeneity of the influence from energy structure in China. From the spillover effect, we can know that the energy structure can promote the $T C$ in the East, but it is unfavorable to the $T C$ in the northeast and the middle region.

\subsubsection{Ownership}

The structure of ownership has increased the regional difference on northeast $T C$ and central EFF. And we can know from spillover effect that the structure of ownership hinders the development of EFF in northeast and TC in east China.

\subsubsection{Industrial Structure}

From regional level, the rise in industrial proportion will increase the difference of the regional EFF except for the east; From regional level, the total effect, direct effect and spillover effect of industrial structure are negative in nationwide. This phenomenon illustrates that the structure of industry not merely expands the divergence of $E F F$, but also inhibits the growth of $E F F$. This negative effect in the middle is more obvious. The central region of the industry relies heavily on local resources, which is unfavorable to the development of local high and new technology industries. This "resource curse" (Sachs et al. [37]) also illustrates the importance of Innovation activity to the improvement of central EFF, similarly, the industrial structure inhibits EFF growth in the west and northeast, and further increases the regional region gap in $E F F$. In east, the total effect of $T C$ is positive, and indicates that the industrial structure can promote the convergence of TC. And we can know from the spillover effect that the eastern industrial cluster has promoted the technological progress of the region; the total effect of Industrial structure to $T C$ is negative due to the convergence of industrial structure in north- 
east. Northeast industry does not show obvious industrial echelon, while has a strong competitive in the regional development. Therefore, the proportion of industry rising suppresses the regional technology progress, and increase the development gap in northeast.

\subsubsection{Urbanization}

The level of urbanization only has significant effect on the $T C$ and $E F F$ in northeast. The total effect and spillover effect of $E F F$ in Northeast China is negative, which indicates that the improvement of urbanization level occurs in relatively developed provinces, and thus, the urbanization increases the technical efficiency gap between developed provinces and backward provinces; The total effect and spillover effect on northeast $T C$ are positive, which means that the urbanization can promote the industrial upgrading of other provinces in the technological innovation, and then narrow the technological gap in northeast.

\subsubsection{FDI}

The empirical results show that the FDI isn't the dynamic to promote the convergence of EFF and TC in China. The regression results, moreover, are not significant in the middle and western regions, it is shows that the impact of FDI on technical efficiency has not been shown in the middle area and west, consisting with the conclusion of Guo [38]. From the direct effect and spillover effect, FDI can promote the EFF and TC in Northeast region as well as the TC in East.

\subsection{Convergence Analysis of TFP}

Table 5 shows that the productivity presents the convergence trend except for diffusion in east and northeast. In spite of the existence of further expansion in the productivity difference in northeast and east, the more stable trend of convergence presented in the western and central area plays a major role in the productivity nationwide. Hence, from the perspective of the full sample nationwide, the productivity is convergent. Since TFP is a comprehensive result of $E F F$ and $T C$, the regression results of $T F P$ can be regarded as a comprehensive effect of variables on $T C$ and $E F F$.

\subsubsection{Innovation Activity}

Technology has a negative gross effect in the east but a positive in the west. It indicates that innovation activities accelerate the diffusion of TFP in the East, while the convergence of TFP in the West. Although the effect of innovation activities is not significant in some certain areas, we can know from the coefficient that it does indeed improve the productivity. For the whole country, technology promotes the growth of EFF and TC. Equation (4) proves empirically that innovation-activities promote the growth of TFP. We can get the consistent results from other regions. It's worth mentioning that different regions have their own characteristics. The promotion on TFP derived from eastern innovation activities is not balanced in this region; Innovation activities show strong positive externalities in the northeast; In the west, innovation activities stimulates TFP 
Table 5. Spatial Durbin model with spatial fixed effects of TFP.

\begin{tabular}{cccccc}
\hline Variable & Countrywide & Northeast & East & West & Central \\
\hline$T E P_{t-1}$ & $0.7059^{* *}$ & 0.1086 & 0.1693 & $0.3484^{* * *}$ & $0.3750^{* * *}$ \\
& $(0.0860)$ & $(0.1650)$ & $(0.1190)$ & $(0.1320)$ & $(0.0790)$ \\
Patent & 0.0005 & 0.0295 & $-0.0205^{* *}$ & 0.0082 & $0.1927^{* *}$ \\
& $(0.0140)$ & $(0.0520)$ & $(0.0090)$ & $(0.0160)$ & $(0.0960)$ \\
Energy & -0.125 & 0.0241 & $0.1138^{* * *}$ & -0.0408 & $-0.4858^{* * *}$ \\
& $(0.1020)$ & $(0.1310)$ & $(0.0270)$ & $(0.0640)$ & $(0.0240)$ \\
Ownership & -0.0353 & $-0.1851^{* *}$ & 0.2157 & -0.1315 & $-0.2294^{* *}$ \\
& $(0.0870)$ & $(0.0720)$ & $(0.1760)$ & $(0.1030)$ & $(0.1140)$ \\
Industrial & -0.172 & $-2.4337^{* * *}$ & 0.5612 & -0.2237 & $-4.3257^{*}$ \\
& $(0.4970)$ & $(0.8290)$ & $(0.3940)$ & $(0.4010)$ & $(2.2400)$ \\
Urbanization & -0.0231 & 0.5024 & 0.3402 & -0.31 & $1.3046^{* *}$ \\
& $(0.4020)$ & $(1.0250)$ & $(0.3560)$ & $(0.6390)$ & $(0.6140)$ \\
FDI & -0.0025 & $0.0419^{*}$ & -0.018 & -0.018 & 0.0387 \\
& $(0.0250)$ & $(0.0220)$ & $(0.0140)$ & $(0.0230)$ & $(0.0350)$ \\
R2 & 390 & 39 & 130 & 143 & 78 \\
& 0.8923 & 0.8059 & 0.2822 & 0.6599 & 0.8484 \\
\hline
\end{tabular}

Notes: ${ }^{*}{ }^{* *},{ }^{* *}$ denote $\mathrm{p}<0.1, \mathrm{p}<0.05$ and $\mathrm{p}<0.01$ respectively; Here only report the total effect of the regression results, the direct effect and spillover effect on TFP is shown in Appendix Table A8 and Table A9.

growth by promoting $T C$, which direct effect is obvious; Similar to the northeast, innovation activities in the central region also presents positive externalities, but it can promote the convergence of $T F P$ in this area differently.

\subsubsection{Energy Structure}

The energy structure in the eastern region has a positive effect on $T F P$, which indicates that the energy structure can promote the TFP convergence. In the northeast, both the total effect and direct effect are negative, indicating that the increasing proportion of raw coal expenditure goes against the TFP improvement. This consists with the above analysis of $E F F$ and $T C$ in the northeast; Similar to the northeast, the energy structure in the central region performs to expand the TFP difference, and inhibits the growth of $T F P$, which is due to the specific industrial structure; In addition, the effect of energy structure is not significant on the TFP convergence and growth in the western region. Because of the heterogeneity of different regions, the role of energy structure on convergence is not significant in the whole China.

\subsubsection{Ownership}

State-owned enterprises accelerate the TFP diffusion in the northeast and central regions. The structure of ownership has a negative direct effect on the TFP improvement in the northeast and east regions. In the east of China, the more perfect mechanism of 
market economy is more efficient. Especially in the northeast, the loss of state owned enterprises is serious, which hinders the economic development. In addition, the ownership structures in the west and the central region show negative spillover effects, which may be due to the imperfect management of state-owned ingredients. Local protectionism in the central region blocks the circulation of factors such as capital and technology, further influencing the productivity improvement. The analysis of the $E F F$ in the central region also confirms this statement. The economy in the west is mainly driven by government investments. However, the government-oriented economic mode is unitary and can't support economic growth. Therefore, the rise of the proportion of the state-owned structure in the western region is not assistant to the TFP.

\subsubsection{Industrial Structure}

The industrial structure has a significant negative total effect in the northeast and central regions, which shows that the industrial structure has increased the diffusion of $T F P$ in these areas. The declining industrial environment and disordered market competition restrain the TFP in northeast. The resource-dependent industry structure in the central region also inhibits the growth of TFP. Industrial clusters in the east, besides, are conducive to the growth of TFP.

\subsubsection{Urbanization}

Urbanization level is significantly positive in central region, showing the positive spillover effect. It declares urbanization can promote central TFP growth, and further narrows the development gap; In the west, there is no such spillover effect, but the direct effect is positive on the local provinces; Although the urbanization level is not significant on northeast, it really promote the northeast TFP because of the effect on $T C$ and $E F F$.

\subsubsection{FDI}

FDI only promotes the convergence of TFP in northeast, and shows the positive spillover effect, which indicates that the introduction of FDI can stimulate the improvement of TFP in the surrounding areas, and further narrow the gap of regional development; FDI shows negative spillover effect in the east, due to the provinces which introduced the FDI are more developed provinces, FDI has increased the gap between the developed regions and the relatively backward regions; For the central and western regions, FDI showed a negative direct effect, reflecting that the introduction of foreign capital is not conducive to the improvement of TFP. It supports the "Pollution Haven" Hypothesis in a certain.

\section{Conclusions}

In the current critical situation of resources and environment, how should Chinese economy achieve sustainable growth and narrow the development gap among regions? Based on this question, this paper uses the DEA model to measure the total factor productivity of China provinces and its decomposition in the period of 1999-2012, and 
analyzes the spatial convergence of economic growth in China using the spatial Durbin model. The study finds as follow:

From 1999 to 2012, Chinese total factor productivity has a rising trend, which is mainly derived by technical improvement; Technological-backward provinces are mainly in the northeast, while the provinces with the fast technology progress are mainly in the eastern region, and shows that the development of China is not balanced. Productivity has conditional convergence nationwide. It means that the gap in productivity growth among the regions of China is shrinking. There are "club" convergences in the central and western regions, but in the northeast and east the convergence of different regions is affected by different factors, which shows that there is a huge difference in the economic growth of various regions in China.

The innovation activity has promoted the efficiency of all regions. This confirms that the "innovation-driven" strategy, which is implemented to guide the regional economic innovation development, is reasonable and prospective. The energy structure promotes the growth of productivity in the east, which shows that the industrial structure of the eastern region can utilize energy better and get greater economic benefits by lower down the pollution cost. However, due to the fact that the industrial structure of northeast and central region over relies on energy, the uses of raw coal aren't conducive to productivity growth. "Resource curse" exists from northeast and central region.

The industrial structure promotes the productivity growth in the northeast and central China, and inhibits the growth of productivity in the northeast, central and western regions. While in the east, it is shown as a driving effect on TFP. This shows that the industrial structure of the northeast, central and western regions should be adjusted. The central and western region can learn from the industrial development mode of east, giving full play to the regional characteristics such as endowment advantages of resource, and further narrow its development gap with the eastern developed region.

The state-owned enterprises are the key to TFP growth in all regions. The government should adjust the guidance to strengthen the economic cooperation among regions and jointly promote the long-term economic growth regionally; The injection of FDI makes the northeast accumulate some capital and achieve further technology improvement, which contributes to the northeast economic growth, but there is a "pollution heaven" in the central and western region; Moreover, urbanization promotes the productivity of hinterland, showing the importance of urbanization in inland areas.

\section{Acknowledgements}

The authors are grateful to Jinan University as this work was funded by case study projects of Enterprise transformation development of the institute for enterprise development, Jinan University (No. 12).

\section{References}

[1] Chow, G. (1993) Capital Formation and Economic Growth in China. Quarterly Journal of Economics, 108, 809-842. http://dx.doi.org/10.2307/2118409 
[2] Park, A. (2010) Migration and Urban Poverty and Inequality in China. China Economic Journal, 3, 49-67. http://dx.doi.org/10.1080/17538963.2010.487351

[3] Liu, W. and Zhang H. (2008) Changes in Industrial Structure and Technology Progress in China Economic Growth. Economic Research Journal, 11, 13-20.

[4] Yao, Z. (2010) Factor Reallocation Effect and Productivity in China's Economic Growth, 1985-2007. Chinese Economy, 43, 44-70. http://dx.doi.org/10.2753/CES1097-1475430103

[5] Li, X. and Lu, X. (2007) Structural Change and Productivity Growth in China Manufacturing. The World Economy, 5, 55-69.

[6] Mitze, T. and Özyurt, S. (2014) The Spatial Dimension of Trade- and FDI-Driven Productivity Growth in Chinese Provinces: A Global Cointegration Approach. Growth and Change, 45, 263-291. http://dx.doi.org/10.1111/grow.12042

[7] Yao, Z. (2015) Productivity Growth and Industrial Structure Adjustment: An Analysis of China's Provincial Panel Data. The Chinese Economy, 48, 253-268.

http://dx.doi.org/10.1080/10971475.2015.1044848

[8] Yu, M. (2010) China's Trade Liberalization and Productivity of Manufacturing Enterprises. Economic Studies, 12, 97-100.

[9] Mankiw, N. and Weil, R. (1992) A Contribution to the Empirics of Economic Growth. Quarterly Journal of Economics, 107, 407-437. http://dx.doi.org/10.2307/2118477

[10] Bo, S. and Liangyue, Z. (2008) Analysis on Convergence of Regional Energy Efficiency in China. Contemporary Finance \& Economics, 2, 17-21.

[11] Liu, Y. (2009) Exploring the Relationship between Urbanization and Energy Consumption in China Using ARDL (Autoregressive Distributed Lag) and FDM (Factor Decomposition Model). Energy, 34, 1846-1854. http://dx.doi.org/10.1016/j.energy.2009.07.029

[12] Liu, Z. (2011) The Calculation and Convergence Analysis of Regional Total Factor Energy Efficiency: An Empirical Study Based on Cross-Province Panel Data in China. Journal of China University of Geosciences, 27, 7-12.

[13] Ma, D., Chen, Z. and Wang, L. (2014) Convergence Analysis of China's Interprovincial International Trade from the Perspective of Spatial Effects. Pakistan Journal of Statistics, 30, 401-424.

[14] Lemoine, F., Poncet, S. and Ünal, D. (2015) Spatial Rebalancing and Industrial Convergence in China. China Economic Review, 34, 39-63. http://dx.doi.org/10.1016/j.chieco.2015.03.007

[15] Caves, D.W., Christensen, L.R. and Diewert, W.E. (1982) The Economic Theory of Index Numbers and the Measurement of Input, Output, and Productivity. Econometrica, 50, 1393-1414. http://dx.doi.org/10.2307/1913388

[16] Ray, S.C. and Desli, E. (1997) Productivity Growth, Technical Progress, and Efficiency Change in Industrialized Countries: Comment. The American Economic Review, 87, 10331039.

[17] Chung, Y.H., Färe, R. and Grosskopf, S. (1997) Productivity and Undesirable Outputs: A Directional Distance Function Approach. Journal of Environmental Management, 51, 229240. http://dx.doi.org/10.1006/jema.1997.0146

[18] Shestalova, V. (2003) Sequential Malmquist Indices of Productivity Growth: An Application to OECD Industrial Activities. Journal of Productivity Analysis, 19, 211-226. http://dx.doi.org/10.1023/A:1022857501478

[19] Chen, Y.A. (2003) Non-Radial Malmquist Productivity Index with an Illustrative Application to Chinese Major Industries. International Journal of Production Economics, 83, 27 35. http://dx.doi.org/10.1016/S0925-5273(02)00267-0 
[20] Pastor, J.T. and Lovell, C.A.K. (2005) A Global Malmquist Productivity Index. Economics Letters, 88, 266-271. http://dx.doi.org/10.1016/j.econlet.2005.02.013

[21] Pastor, J.T., Asmild, M. and Lovell, C.A.K. (2011) The Biennial Malmquist Productivity Change Index. Socio-Economic Planning Sciences, 45, 10-15. http://dx.doi.org/10.1016/j.seps.2010.09.001

[22] Aparicio, J., Pastor, J.T. and Zofio, J.L. (2013) On the Inconsistency of the Malmquist-Luenberger Index. European Journal of Operational Research, 229, 738-742. http://dx.doi.org/10.1016/j.ejor.2013.03.031

[23] Zou, W., Cai, P., Shen, N. and Lu, C. (2015) The Technology gap of Chinese Regions' Energy Efficiency and Spatial. Journal of Renewable and Sustainable Energy, 7, Article ID: 023124.

[24] Li, G. and Huo, Z. (2010) Total Factor Energy Efficiency of China and Its Convergence. China Population Resources and Environment, 20, 11-16.

[25] Kanekoa, S., Fujiia, H., Sawazub, N. and Fujikurac, R. (2010) Financial Allocation Strategy for the Regional Pollution Abatement Cost of Reducing Sulfur Dioxide Emissions in the Thermal Power Sector in China. Energy Policy, 38, 2131-2141. http://dx.doi.org/10.1016/j.enpol.2009.06.005

[26] Managi, S. and Kaneko, S. (2006) Economic Growth and the Environment in China: An Empirical Analysis of Productivity. International Journal of Global Environment Issues, 6, 89-133. http://dx.doi.org/10.1504/IJGENVI.2006.009402

[27] Watanabe, M. and Tanaka, K. (2007) Efficiency Analysis of Chinese Industry: A Directional Distance Function Approach. Energy Policy, 35, 6323-6331.

http://dx.doi.org/10.1016/j.enpol.2007.07.013

[28] Charnes, A., Cooper, W. and Rhodes, E. (1978) Measuring the Efficiency of DecisionMaking Units. European Journal of Operational Research, 2, 429-444. http://dx.doi.org/10.1016/0377-2217(78)90138-8

[29] Chambers, R.G., Chung, Y. and Färe, R. (1996) Benefit and Distance Functions. Journal of Economic Theory, 70, 407-419. http://dx.doi.org/10.1006/jeth.1996.0096

[30] Du, M., Wang, B. and Wu, Y. (2014) Sources of China's Economic Growth: An Empirical Analysis Based on the BML Index with Green Growth Accounting. Sustainability, 6, 59836004. http://dx.doi.org/10.3390/su6095983

[31] Barro, J.R. and Sala-I-Martin, X. (1992) Convergence. Journal of Political Economy, 100, 223-240. http://dx.doi.org/10.1086/261816

[32] Anselin, L., Gallo, J. and Jayet, H. (2008) The Econometrics of Panel Data. Springer, Berlin.

[33] Pace, R.K. and LeSage, J.P. (2009) Introduction to Spatial Econometrics. Chapman \&Hall, Boca Raton.

[34] National Bureau of Statistics (2011) China Statistical Yearbook. China Statistical Press, Beijing.

[35] Department of Industry and Transport Statistics, National Bureau of Statistics (NBS), Energy Bureau, National Development and Reform Commission (NDRC) (2011) China Energy Statistical Yearbook. China Statistical Press, Beijing. (In Chinese)

[36] Wu, Y. (2004) Openness, Productivity and Growth in the APEC Economies. Empirical Economics, 29, 593-604. http://dx.doi.org/10.1007/s00181-004-0200-1

[37] Sachs, J.D. and Warner, A.M. (2001) The Curse of Natural Resources. European Economic Review, 45, 827-838. http://dx.doi.org/10.1016/S0014-2921(01)00125-8

[38] Guo, Z. and Yang, X. (2008) Different Impacts of Foreign Direct Investment on Economic Growth among China's Eastern, Middle and Western Regions: An Empirical Test of the Provincial Data from 1990 to 2004. Nankai Economic Studies, 1, 75-86. 


\section{Appendix}

Table A1. Correlation test of SDM (EFF).

\begin{tabular}{|c|c|c|c|c|c|c|}
\hline & & Nationwide & Northeast & East & West & Central \\
\hline \multirow{2}{*}{ LR test } & Spatial fixed & 30.9523 & $9.5288^{\star *}$ & $8.8076^{\star \star}$ & $4.4938^{\star * \star}$ & 5.6171 \\
\hline & Time fixed & $27.0802^{\star *}$ & 17.1082 & $32.0296^{* * *}$ & 11.9144 & $34.0069^{* * *}$ \\
\hline \multirow{2}{*}{ LM test (robust) } & spatial lag & $7.8009^{* * *}$ & $9.4342^{* * *}$ & $8.7216^{* * *}$ & 1.7081 & $2.0128^{\star * *}$ \\
\hline & spatial error & $11.8502^{\star *}$ & $13.0144^{* *}$ & $12.1879^{* * *}$ & $5.8694^{* *}$ & $4.1030^{\star *}$ \\
\hline \multirow{2}{*}{ Wald test } & spatial lag & $25.9386^{* * *}$ & $15.1201^{\star *}$ & $18.5121^{\star * *}$ & $14.0831^{*}$ & $12.1278^{\star}$ \\
\hline & spatial error & $14.4481^{\star *}$ & $14.4200^{\star *}$ & $16.3334^{\star *}$ & 3.2752 & $19.4052^{\star * *}$ \\
\hline
\end{tabular}

Table A2. Correlation test of SDM (TC).

\begin{tabular}{ccccccc}
\hline & & Nationwide & Northeast & East & West & Central \\
\hline \multirow{2}{*}{ LR test } & Spatial fixed & $78.3506^{* * *}$ & $24.6279^{* * *}$ & $21.1314^{* *}$ & $23.7641^{* * *}$ & $49.2122^{* * *}$ \\
& Time fixed & 14.2177 & 18.694 & $38.3150^{* * *}$ & 13.022 & 17.0377 \\
& spatial lag & $8.2761^{* * *}$ & $6.2268^{* *}$ & $8.2053^{* * *}$ & $8.4072^{* * *}$ & $10.4722^{\star * *}$ \\
LM test (robust) & spatial error & $12.5335^{* *}$ & $5.6751^{* *}$ & $11.8276^{* * *}$ & $11.9061^{* * *}$ & $14.3289^{* * *}$ \\
& spatial lag & $22.9030^{* * *}$ & $15.7858^{* *}$ & $17.2399^{* *}$ & $13.8574^{*}$ & $14.6735^{* *}$ \\
Wald test & spatial error & $20.9467^{* * *}$ & $21.8075^{* * *}$ & $15.3271^{* *}$ & $14.2594^{* *}$ & $14.2867^{* *}$ \\
\hline
\end{tabular}

Table A3. Correlation test of SDM (TFP).

\begin{tabular}{ccccccc}
\hline & & Nationwide & Northeast & East & West & Central \\
\hline \multirow{2}{*}{ LR test } & Spatial fixed & $59.7511^{* * *}$ & $24.6279^{* * *}$ & 9.2095 & $24.5453^{* * *}$ & $50.5407^{* * *}$ \\
& Time fixed & $28.1792^{* * *}$ & 18.694 & $59.6224^{* * *}$ & $20.0697^{* * *}$ & 15.4246 \\
& spatial lag & $7.8719^{* * *}$ & 2.2268 & 2.0829 & 1.2221 & $6.9778^{* * *}$ \\
\multirow{2}{*}{ LM test (robust) } & spatial error & $11.8492^{* *}$ & $4.6751^{* *}$ & $6.044^{* *}$ & $15.3614^{* * *}$ & $6.2578^{* *}$ \\
& spatial lag & $13.3461^{*}$ & $39.0109^{* * *}$ & $12.9337^{*}$ & $33.7675^{* * *}$ & $13.6889^{*}$ \\
Wald test & spatial error & $15.1170^{* *}$ & $25.5371^{* * *}$ & 3.8885 & 1.7259 & $15.035^{* *}$ \\
\hline
\end{tabular}

Table A4. Spatial Durbin model of EFF(direct effect).

\begin{tabular}{cccccc}
\hline Variable & Nationwide & Northeast & East & West & Central \\
\hline$E F F_{t-1}$ & $-0.0589^{\star *}$ & $-0.3595^{\star * *}$ & $-0.1528^{\star *}$ & -0.0084 & $-0.0839^{\star * \star}$ \\
& $(0.0240)$ & $(0.0550)$ & $(0.0710)$ & $(0.0520)$ & $(0.0180)$ \\
Patent & 0.0015 & $-0.0382^{* * *}$ & 0.002 & -0.0015 & 0.0595 \\
& $(0.0050)$ & $(0.0100)$ & $(0.0080)$ & $(0.0060)$ & $(0.0480)$ \\
Energy & 0.0413 & -0.0011 & 0.0159 & -0.0018 & $0.3608^{\star * *}$ \\
& $(0.0270)$ & $(0.0960)$ & $(0.0230)$ & $(0.0490)$ & $(0.1080)$ \\
Ownership & -0.0148 & $-0.3130^{* * *}$ & 0.0192 & 0.0296 & 0.0405 \\
\hline
\end{tabular}


Continued

\begin{tabular}{cccccc}
\hline & $(0.0250)$ & $(0.0900)$ & $(0.0380)$ & $(0.0530)$ & $(0.0580)$ \\
Industrial & $-0.0956^{\star}$ & -0.0091 & 0.068 & $-0.1361^{*}$ & $-0.6726^{* *}$ \\
& $(0.0490)$ & $(0.2460)$ & $(0.0940)$ & $(0.0800)$ & $(0.3310)$ \\
Urbanization & 0.0574 & -0.709 & 0.041 & $0.2034^{\star}$ & 0.3126 \\
& $(0.0630)$ & $(0.7450)$ & $(0.0640)$ & $(0.1060)$ & $(0.1970)$ \\
FDI & 0.0017 & $0.0184^{* *}$ & -0.0068 & 0.0062 & -0.0286 \\
& $(0.0040)$ & $(0.0080)$ & $(0.0060)$ & $(0.0050)$ & $(0.0260)$ \\
\hline
\end{tabular}

Table A5. Spatial Durbin model of EFF(spillover effect).

\begin{tabular}{cccccc}
\hline Variable & Nationwide & Northeast & East & West & Central \\
\hline$E F F_{t-1}$ & -0.0046 & $0.0573^{* *}$ & 0.0177 & -0.0039 & $0.0191^{* * *}$ \\
& $(0.0050)$ & $(0.0260)$ & $(0.0140)$ & $(0.0090)$ & $(0.0040)$ \\
Patent & $0.0352^{* *}$ & $0.0400^{* *}$ & 0.0126 & 0.0184 & $0.1562^{* *}$ \\
& $(0.0150)$ & $(0.0180)$ & $(0.0080)$ & $(0.0180)$ & $(0.0620)$ \\
Energy & 0.0021 & -0.076 & -0.0021 & -0.0002 & $-0.0820^{* * *}$ \\
& $(0.0030)$ & $(0.1010)$ & $(0.0030)$ & $(0.0070)$ & $(0.0250)$ \\
Ownership & -0.0646 & $0.2339^{* * *}$ & 0.1166 & -0.1074 & $-0.2287^{* * *}$ \\
& $(0.0840)$ & $(0.0370)$ & $(0.0940)$ & $(0.1750)$ & $(0.0770)$ \\
Industrial & $-0.7854^{* *}$ & -0.1648 & -0.1138 & -0.68 & $-4.1458^{*}$ \\
& $(0.3920)$ & $(0.3130)$ & $(0.2750)$ & $(0.4520)$ & $(2.2040)$ \\
& 0.041 & -0.5713 & -0.1119 & 0.1394 & 0.6609 \\
Urbanization & $(0.3440)$ & $(0.4330)$ & $(0.1400)$ & $(0.3660)$ & $(0.6060)$ \\
& -0.0108 & -0.0031 & -0.0023 & 0.0067 & 0.0777 \\
FDI & $(0.0270)$ & $(0.0040)$ & $(0.0190)$ & $(0.0300)$ & $(0.0660)$ \\
& & & & &
\end{tabular}

Table A6. Spatial Durbin model of TC (direct effect).

\begin{tabular}{cccccc}
\hline Variable & Nationwide & Northeast & East & West & Central \\
\hline$T C_{t-1}$ & $0.3827^{* * *}$ & -0.082 & $-0.2120^{* * *}$ & 0.1827 & $0.2637^{* * *}$ \\
& $(0.0860)$ & $(0.1940)$ & $(0.0740)$ & $(0.1130)$ & $(0.0750)$ \\
Patent & 0.0116 & $-0.0580^{* *}$ & 0.0039 & $0.0269^{* * *}$ & $-0.0347^{*}$ \\
& $(0.0110)$ & $(0.0250)$ & $(0.0110)$ & $(0.0100)$ & $(0.0210)$ \\
Energy & -0.1376 & $-0.3558^{* *}$ & $0.0878^{* * *}$ & -0.042 & $-0.8486^{* * *}$ \\
& $(0.0870)$ & $(0.1790)$ & $(0.0320)$ & $(0.1200)$ & $(0.1820)$ \\
Ownership & 0.0246 & 0.0598 & $-0.1414^{* *}$ & 0.0592 & 0.0335 \\
& $(0.0450)$ & $(0.1450)$ & $(0.0600)$ & $(0.1130)$ & $(0.1100)$ \\
Industrial & 0.1113 & 0.4097 & $0.1869^{* * *}$ & -0.1034 & -0.4052 \\
\hline
\end{tabular}


Continued

\begin{tabular}{cccccc}
\hline & $(0.1170)$ & $(0.3360)$ & $(0.0600)$ & $(0.1830)$ & $(0.5970)$ \\
Urbanization & -0.07 & -0.3158 & -0.0417 & 0.0154 & -0.2202 \\
& $(0.1140)$ & $(0.8120)$ & $(0.0810)$ & $(0.1960)$ & $(0.1750)$ \\
\multirow{2}{*}{ FDI } & -0.0058 & -0.0003 & $0.0155^{\star}$ & -0.0155 & 0.028 \\
& $(0.0060)$ & $(0.0100)$ & $(0.0090)$ & $(0.0100)$ & $(0.0290)$ \\
\hline
\end{tabular}

Table A7. Spatial Durbin model of $T C$ (spillover effect).

\begin{tabular}{cccccc}
\hline Variable & Nationwide & Northeast & East & West & Central \\
\hline$T C_{t-1}$ & $0.3827^{* * *}$ & -0.082 & $-0.2120^{* * *}$ & 0.1827 & $0.2637^{* * *}$ \\
& $(0.0860)$ & $(0.1940)$ & $(0.0740)$ & $(0.1130)$ & $(0.0750)$ \\
Patent & 0.0116 & $-0.0580^{* *}$ & 0.0039 & $0.0269^{* * *}$ & $-0.0347^{*}$ \\
& $(0.0110)$ & $(0.0250)$ & $(0.0110)$ & $(0.0100)$ & $(0.0210)$ \\
Energy & -0.1376 & $-0.3558^{* *}$ & $0.0878^{* * *}$ & -0.042 & $-0.8486^{* * *}$ \\
& $(0.0870)$ & $(0.1790)$ & $(0.0320)$ & $(0.1200)$ & $(0.1820)$ \\
Ownership & 0.0246 & 0.0598 & $-0.1414^{* *}$ & 0.0592 & 0.0335 \\
& $(0.0450)$ & $(0.1450)$ & $(0.0600)$ & $(0.1130)$ & $(0.1100)$ \\
Industrial & 0.1113 & 0.4097 & $0.1869^{* * *}$ & -0.1034 & -0.4052 \\
& $(0.1170)$ & $(0.3360)$ & $(0.0600)$ & $(0.1830)$ & $(0.5970)$ \\
Urbanization & -0.07 & -0.3158 & -0.0417 & 0.0154 & -0.2202 \\
& $(0.1140)$ & $(0.8120)$ & $(0.0810)$ & $(0.1960)$ & $(0.1750)$ \\
FDI & -0.0058 & -0.0003 & $0.0155^{*}$ & -0.0155 & 0.028 \\
& $(0.0060)$ & $(0.0100)$ & $(0.0090)$ & $(0.0100)$ & $(0.0290)$ \\
\hline
\end{tabular}

Table A8. Spatial Durbin model of TFP(direct effect).

\begin{tabular}{|c|c|c|c|c|c|}
\hline Variable & Nationwide & Northeast & East & West & Central \\
\hline \multirow[t]{2}{*}{$T E P_{t-1}$} & $0.6109^{* * *}$ & 0.111 & 0.1083 & $0.3697^{\star * *}$ & $0.4959^{* * *}$ \\
\hline & $(0.0460)$ & $(0.1690)$ & $(0.0760)$ & $(0.1270)$ & $(0.0670)$ \\
\hline \multirow[t]{2}{*}{ Patent } & 0.0064 & $-0.0724^{\star \star *}$ & 0.0062 & $0.0171^{\star \star}$ & 0.0318 \\
\hline & $(0.0100)$ & $(0.0180)$ & $(0.0100)$ & $(0.0070)$ & $(0.0340)$ \\
\hline \multirow[t]{2}{*}{ Energy } & -0.1108 & $-0.2666^{\star *}$ & $0.0724^{* * *}$ & -0.0467 & $-0.6542^{* * *}$ \\
\hline & $(0.0910)$ & $(0.1280)$ & $(0.0150)$ & $(0.0700)$ & $(0.0780)$ \\
\hline \multirow[t]{2}{*}{ Ownership } & -0.0023 & $-0.2626^{\star *}$ & $-0.0841^{\star *}$ & 0.0622 & 0.0959 \\
\hline & $(0.0320)$ & $(0.1310)$ & $(0.0370)$ & $(0.0680)$ & $(0.1100)$ \\
\hline \multirow[t]{2}{*}{ Industrial } & 0.0029 & -0.0383 & $0.2081^{\star * *}$ & $-0.1655^{\star}$ & -1.0171 \\
\hline & $(0.0880)$ & $(0.2730)$ & $(0.0540)$ & $(0.1010)$ & $(0.6460)$ \\
\hline \multirow[t]{2}{*}{ Urbanization } & -0.0405 & $-0.3626^{\star}$ & 0.0237 & $0.1455^{\star}$ & -0.2276 \\
\hline & $(0.1020)$ & $(0.2090)$ & $(0.0920)$ & $(0.0830)$ & $(0.1770)$ \\
\hline \multirow[t]{2}{*}{ FDI } & $-0.0050^{\star}$ & 0.0218 & 0.0063 & $-0.0089^{\star}$ & -0.01 \\
\hline & $(0.0030)$ & $(0.0180)$ & $(0.0040)$ & $(0.0050)$ & $(0.0100)$ \\
\hline
\end{tabular}


Table A9. Spatial Durbin model of TFP(spillover effect).

\begin{tabular}{cccccc}
\hline Variable & Nationwide & Northeast & East & West & Central \\
\hline$T E P_{t-1}$ & 0.095 & -0.0024 & 0.0609 & -0.0213 & $-0.1209^{* * *}$ \\
& $(0.0830)$ & $(0.0050)$ & $(0.0450)$ & $(0.0370)$ & $(0.0440)$ \\
Patent & -0.0059 & $0.1019^{* *}$ & $-0.0267^{\star * *}$ & -0.0089 & $0.1610^{* *}$ \\
& $(0.0140)$ & $(0.0450)$ & $(0.0100)$ & $(0.0150)$ & $(0.0640)$ \\
Energy & -0.0142 & $0.2908^{* *}$ & $0.0414^{* * *}$ & 0.0059 & $0.1685^{* *}$ \\
& $(0.0220)$ & $(0.1200)$ & $(0.0130)$ & $(0.0100)$ & $(0.0760)$ \\
Ownership & -0.0329 & 0.0775 & $0.2997^{* *}$ & $-0.1937^{* *}$ & $-0.3252^{* * *}$ \\
& $(0.0810)$ & $(0.1740)$ & $(0.1470)$ & $(0.0820)$ & $(0.1150)$ \\
Industrial & -0.1749 & $-2.3954^{* * *}$ & 0.3532 & -0.0582 & $-3.3086^{* *}$ \\
& $(0.4610)$ & $(0.6580)$ & $(0.3580)$ & $(0.4300)$ & $(1.6820)$ \\
& 0.0174 & 0.8649 & 0.3166 & -0.4555 & $1.5321^{* *}$ \\
Urbanization & $(0.3330)$ & $(1.2270)$ & $(0.2770)$ & $(0.6930)$ & $(0.6690)$ \\
& 0.0025 & $0.0200^{* * *}$ & $-0.0243^{*}$ & -0.0091 & 0.0487 \\
& $(0.0250)$ & $(0.0040)$ & $(0.0140)$ & $(0.0210)$ & $(0.0370)$ \\
\hline FDI & & & &
\end{tabular}

Submit or recommend next manuscript to SCIRP and we will provide best service for you:

Accepting pre-submission inquiries through Email, Facebook, LinkedIn, Twitter, etc.

A wide selection of journals (inclusive of 9 subjects, more than 200 journals)

Providing 24-hour high-quality service

User-friendly online submission system

Fair and swift peer-review system

Efficient typesetting and proofreading procedure

Display of the result of downloads and visits, as well as the number of cited articles

Maximum dissemination of your research work

Submit your manuscript at: http://papersubmission.scirp.org/

Or contact jssm@scirp.org 